\title{
CAPÍTULO 21: INVESTIGAÇÃO DAS PROPRIEDADES FISÍCO-QUÍMICAS E MORFOLÓGICAS DA CASTANHA DE CERU ( ALLANTOMA LINEATA) PARA APLICAÇÃO EM BISCOITO
}

\author{
CHAPTER 21: INVESTIGATION OF THE PHYSICOCHEMICAL AND \\ MORPHOLOGICAL PROPERTIES OF THE CHESTNUT OF CERU (ALLANTOMA \\ LINEATA) FOR APPLICATION IN CRACKERS
}

\section{CAPÍTULO 21: INVESTIGACIÓN DE LAS PROPIEDADES FISICOQUÍMICAS Y MORFOLÓGICAS DEL CASTAÑO DE CERU (ALLANTOMA LINEATA) PARA APLICACIÓN EN GALLETAS}

Edgardi Silva Contente ${ }^{1}$, Ildes Ribeiro Alves ${ }^{2}$; Giselle Cristine Melo Aires ${ }^{3}$; Suane Corrêa Barbosa ${ }^{4}$; Diego Aires da Silva ${ }^{5}$

\section{DOI: $\underline{\text { https://doi.org/10.31692/978-65-88970-19-5.317-338 }}$}

\section{RESUMO}

A Allantoma lineata ou castanha de Ceru, que é uma espécie amazônica característica das regiões de florestas de várzeas, são numerosas, finas e compridas, possuem uma aparência muito similar a uma lasca de madeira, muitas vezes sendo confundida com um galho ou pedaço de lenha. $\mathrm{O}$ objetivo deste trabalho foi caracterizar física e quimicamente, a castanha da espécie Allantoma lineata (Ceru) coletadas no interior do município de Cametá e avaliar o seu potencial nutritivo através do seu beneficiamento. Para tal, realizou-se análises de caracterização e biometria, avaliando o peso, largura, comprimento e altura das sementes, quantificando o teor de lipídio, proteína, umidade e cinzas, tanto para a amêndoa quanto para a casca da castanha de Ceru. Também foram analisadas as características físico-químicas do biscoito, quantificando o teor de acidez, $\mathrm{pH}$ e umidade. Os resultados da análise biométrica apontaram que o peso, largura, comprimento e altura das sementes, obtiveram médias de $0,86 \mathrm{~g}, 6,03 \mathrm{~mm}, 8,26 \mathrm{~mm}$ e $47,5 \mathrm{~mm}$, respectivamente. Houve uma acentuada distribuição de frequência das características avaliadas nas sementes, com exceção do parâmetro comprimento, onde ficou concentradas principalmente entre os valores de $6,15 \mathrm{~mm}$ a $9,07 \mathrm{~mm}$, relevando um potencial para a conservação e melhoramento desta espécie. Para as análises físico-química da castanha de Ceru os resultados foram $57 \%$ de lipídios, $24 \%$ de proteínas e valor calórico $680,20 \mathrm{kcal}$, números bem semelhantes a outras castanhas consumidas na região. Na avaliação da composição da casca da castanha de Ceru foi possível observar que as médias do teor de umidade, cinzas, lipídios e proteínas foram $15,97 \%$ e $3,35 \%, 9,56 \%$ e $4,17 \%$ respectivamente. O biscoito foi avaliado quanto a sua umidade $0,68 \%, \mathrm{pH} 6,36$ a uma temperatura de $24{ }^{\circ} \mathrm{C}$ e Acidez 13,89\%. O valor elevado de acidez foi atribuído a oxidação dos óleos presentes no momento da secagem em estufa. Portanto, constata-se que o beneficiamento do cerú é uma alternativa que pode gerar renda para as famílias agroextrativistas

\footnotetext{
${ }^{1}$ Tecnologia de Alimentos, Universidade do Estado do Pará diegoaires@uepa.br

2 Tecnologia de Alimentos, Universidade do Estado do Pará ildes1142@gmail.com

3 Tecnologia de Alimentos, Universidade do Estado do Pará edgardi433@gmail.com

${ }^{4}$ Tecnologia de Alimentos, Universidade do Estado do Pará suanecorrea1535@gmail.com

${ }^{5}$ Tecnologia de Alimentos, Universidade do Estado do Pará giselle.aires@uepa.br 
localizadas nas regiões de várzea do município de Cametá/PA.

Palavras-Chave: Allantoma lineata, semente oleaginosa.

\section{INTRODUÇÃO}

As sementes, as nozes e as castanhas comestíveis de plantas, têm recebido atenção especial de pesquisadores nos últimos anos, pois possuem um grande acervo, ainda inexplorado, de espécies com potencial alimentício (COSTA et al, 2010). Dentre as quais, a castanha do Brasil (Bertholletia excelsa) é uma espécie bem estabelecida no mercado. O País é um dos maiores produtores mundiais desse fruto, com uma safra média de 35 mil toneladas e uma área natural em torno de 325 milhões de hectares na Amazônia (CARDARELLI \& OLIVEIRA 2000).

As florestas brasileiras possuem uma diversidade de espécies nativas cujos frutos e sementes podem ser utilizados como fontes de nutrientes, sendo, portanto, de extrema importância o estudo dessas fontes alternativas de alimentos (CARVALHO et al, 2012). Desta forma, merece destaque, uma espécie amazônica característica das regiões de florestas de várzeas, a castanha de ceru (Allantoma lineata) (MORI, 2001).

A madeira de ceru é muito utilizada para confecção de diversos produtos da indústria madeireira (SANTOS et al, 2010). Seu fruto é um pixídio cilíndrico semelhante a um copo, medindo de 10 a $15 \mathrm{~cm}$ de comprimento, por 4 a $5 \mathrm{~cm}$ de diâmetro. Na parte superior, possui uma espécie de tampa (opérculo) que segura as amêndoas até o seu amadurecimento e podem conter em média de 8 a 12 amêndoas. Estas são numerosas, finas e compridas, e após serem liberadas são levadas pelo vento e caem no chão ou na água, restando somente o copo oco na árvore (PESCE, 2009). Suas castanhas possuem uma aparência muito similar a uma lasca de madeira, longa e fina, muitas vezes sendo confundida com um galho ou pedaço de lenha. No entanto, seu consumo fica restrito as zonas ribeirinhas visto que a sua coleta é difícil. São facilmente perdidas ao longo das várzeas ou consumidas por outros animais, como pássaros e roedores.

A morfológica de sementes é essencial, pois a biometria pode fornecer informações importantes na conservação e exploração de recursos socio-econômicos e ambientais, permitindo um incentivo contínuo da busca racional e uso eficaz de recursos naturais 
(GUSMÃO et al., 2006). Além disso, a biometria de sementes se tornou uma importante ferramenta na avaliação da variabilidade genética dentro de populações da mesma espécie, que muitas vezes pode estar associado a fatores ambientais (MACEDO et al., 2009). A farinha de castanha é um subproduto com elevado valor proteico, por apresentar diversas vantagens, tem sido muito utilizada em produtos de panificação, como na elaboração de biscoitos (OLIVEIRA, 2017).

Segundo a ANVISA - Agência Nacional de Vigilância Sanitária, na Resolução nº 263, de 22 de setembro de 2005, define biscoitos ou bolachas como produtos obtidos através de mistura de farinha(s), amido(s) e/ou fécula(s) com outros ingredientes, submetidos a processos de amassamento e cocção, podendo ser fermentados ou não. Podendo apresentar cobertura, recheio, formato e textura diversos (BRASIL, 2005).

Portanto, o objetivo deste trabalho é realizar a Caracterização físico-química e o potencial nutritivo após seu beneficiamento de castanha Allantoma lineata (Ceru), oriunda do interior do município de Cametá.

\section{REFERENCIAL TEÓRICO}

\section{Floresta de várzea}

As várzeas amazônicas são áreas inundáveis que ocupam cerca de 25 milhões de hectares (TEIXEIRA \& CARDOSO, 1991), sempre às margens do rio Amazonas, desde a nascente na Cordilheira dos Andes até o seu estuário próximo à Ilha do Marajó, abrangendo inclusive os principais afluentes desta região (RAMOS, 2000).

A várzea amazônica é um ecossistema rico e distinto no que se refere à biodiversidade e diversidade dos recursos naturais, com potencial de uso de madeira, castanha, borracha, palmito, frutos, essências aromáticas, sementes oleaginosas e pescados. Esse ecossistema possui cerca de 400 anos de exploração, com a população local mantendo uma forte Inter relação de dependência com o ambiente aquático e terrestre (RIBEIRO, 2002).

No caso da área de estudo, localizada à jusante da Usina Hidrelétrica de Tucuruí, o ambiente terrestre, precisamente as florestas nativas, que vem originando as Agro florestas, manejadas por famílias ribeirinhas, com a barragem do Rio Tocantins em 1984, assumiu uma 
importância singular na vida das famílias moradoras, fornecendo os alimentos básicos, ocupando a mão-de-obra familiar e possibilitando renda monetária, gerando a dependência dos SAF's (Sistemas Agroflorestais) para a sobrevivência (RIBEIRO, 2002).

Os moradores das várzeas, ao longo dos tempos, adaptaram-se em utilizar os vários produtos e benefícios de suas florestas, pressionados pelo isolamento de suas terras pelas inundações em que estavam sujeitos. Entre as principais riquezas extraídas para consumo próprio e algumas vezes para comercialização, estão os produtos obtidos da exploração de madeira e outros produtos da floresta, denominados comumente de produtos não madeireiros. Ainda assim, muitas espécies consideradas comerciais, não são aproveitadas pelas indústrias (RAMOS, 2000).

Torna-se extremamente importante para as pesquisas básica e aplicada ocorrentes na região Amazônica, onde o desenvolvimento econômico das diversas áreas vem acontecendo de maneira descontrolada e pouco planejada, seguindo uma lógica de interesses particulares. Nesse tipo de desenvolvimento, as regras ecológicas e as inter-relações do meio ambiente são desrespeitadas, resultando num declínio rápido e irreversível da diversidade vegetal e, consequentemente, na diminuição das opções de utilização dos recursos naturais. Para avaliar e melhorar este modelo de desenvolvimento caótico e predatório, é necessária a obtenção de maiores informações sobre a biodiversidade regional (CARVALHO, 1999).

\section{Lecythidaceae}

Segundo Mori \& Prance (1990), essa família conta com 197 espécies neotropicais descritas em 11 gêneros; desse total, 137 pertencem apenas a seis gêneros; a primeira ilustração e descrição dessa família data de 1624-1635, realizadas por Frei Cristóvão, um missionário que vivia no Estado do Maranhão; esse pode ter sido o primeiro a estudar Bertholletia excelsa Humb; \& Bonpl. (Castanha-do-Brasil). Até por volta de 1874, Lecythidaceae não era considerada como família, seus géneros faziam parte de Myrtaceae. Segundo Prance \& Mori (1979), John Miers, nos anos de 1874 e 1875, foi o primeiro a considerar Lecythidaceae como família independente (CARVALHO, 1999).

A importância econômica que as espécies de Lecythidaceae possuem na região Amazônica torna-se evidente através do aproveitamento dos frutos e sementes da castanha-do-brasil (Bertholletia ex-celsa Humb. \& Bonpl.), que por possuírem alto teor de 
proteínas, podem ser usados como alimento e na medicina alternativa (CRAVO, 1995), como também a castanha-sapucaia (Lecythis pisonis Cambess) que além da comercialização de suas sementes, também pode ser aproveitada no paisagismo, pois na época de floração, toda a copa adquire coloração lilás (LORENZI, 1992).

A situação para as sementes de outras espécies Lecythidaceae nativa das florestas tropicais amazônicas é diferente. Nenhum deles é comercializado em escala comercial e pouco se sabe sobre sua composição química. Por causa de seu potencial para servir como uma nova fonte de alimento análises químicas e morfológicas devem ser mais detalhadas para estabelecer o seu verdadeiro potencial. (ANDRADE et al. 1999).

\section{Castanha do Brasil (Bertholletia excelsa)}

A castanheira (Bertholletia excelsa) pertence à família Lecythidaceae e é popularmente conhecida no Brasil como castanheira, castanha-do-pará, castanha-do brasil e castanha da Amazônia. A Árvore é de grande porte, chega a atingir 60 metros de altura, com diâmetro altura do peito medido a $1,30 \mathrm{~m}$ do solo podendo chegar até dois metros, alcançado em torno de 500 anos de vida (SALOMÃO et al., 1995).

Seu fruto, também chamado de ouriço, é uma cápsula de aproximadamente 15 centímetros de diâmetro que se assemelha ao endocarpo do coco no tamanho, seu peso variável podendo atingir de 500 a 1500 g, possuindo de 15 a 24 sementes (castanhas) /ouriço, o que representa cerca de $25 \%$ da massa do mesmo (MÜLLER et al., 1995). A semente possui um formato triangular, com 4 a $7 \mathrm{~cm}$ de comprimento e possui a casca bastante dura e rugosa e como muitas Lecitidáceas. O fruto da castanheira possui opérculo que se desprende com a maturidade do fruto, no entanto, este é considerado funcionalmente indeiscente visto que o opérculo continua dentro do fruto mesmo após este se solta, já que o diâmetro da abertura do opérculo nunca é suficiente para a passagem do conteúdo da fruta (APARÍCIO, 2011).

A Castanha-do-Brasil é um alimento grandemente apreciado pelo seu sabor, e ainda apresenta qualidades nutricionais importantes. É constituída por 60 a 70\% de lipídios, expressivamente de ácidos graxos poli-insaturados, e de 15 a 20\% de proteína de boa qualidade biológica, além de fonte reconhecida de selênio, cálcio, fósforo, magnésio e 
vitaminas do complexo B. Tem sido ainda considerada uma boa fonte nutricional no enriquecimento e produção de alimentos como forma alternativa para alimentação da população local, em função da disponibilidade regional. (CARDARELLI \& OLIVEIRA, 2000; GLÓRIA, 2000; SOUZA, 2004).

\section{Sapucaia (Lecythis pisonis Cambess)}

Conhecida popularmente como castanha-sapucaia, marmita-de-macaco, cumbuca-de-macaco ou simplesmente "sapucaia", esta árvore da família Lecythidaceae tem origem brasileira e ocorre do Ceará até o Rio de Janeiro. Pode atingir 20 a 30 metros de altura, com tronco de 50 a 90 centímetros de diâmetro a altura do peito (LORENZI, 1992).

A semente de sapucaia, Lecythis pisonis Camb, que é popularmente utilizada como parte comestível do fruto no interior do Brasil, principalmente nos Estados de Pernambuco até São Paulo e na Amazônia, supondo-se originária da parte central leste desta região (VALLILO et al, 1998).

As amêndoas aromáticas e oleaginosas da sapucaia podem ser consumidas cruas, cozidas ou assadas, constituindo-se em excelente alimento. Um quilograma destas castanhas fornece aproximadamente 180 sementes e podem substituir, em igualdade de condições, as nozes, amêndoas ou castanhas comuns, prestando-se como ingrediente para doces, confeitos e pratos salgados (CARVALHO et al, 2011).

\section{Ceruzeiro (Allantoma lineata)}

Esta espécie é uma pequena árvore relativamente baixa medindo até $10 \mathrm{~m}$ (Figura 1), que é distribuído em toda a bacia de amazônica, muito frequente em estuário do rio Amazonas. A sua madeira é descrita de ter excelentes propriedades para a fabricação de papel (ANDRADE et al. 1999). 


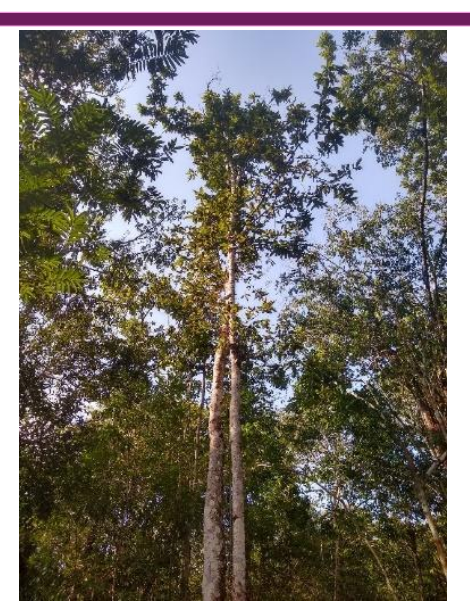

Figura 1 - Ceruzeiro (Allantoma Lineata)

Fonte: Autor (2021).

Segundo Ribeiro (2004), na várzea do Rio Juba afluente do Rio Tocantins, Cametá-PA mostrou que as árvores de Ceruzeiro possuía $0,09 \%$ de densidade relativa em 1 hectare de área (Quadro - 1.) sendo umas das principais espécies envolvida na atividade florestal madeireira, envolvendo as operações extrativas de madeiras em toras destinadas às serrarias ou para uso nas residências.

Quadro 1 - Famílias e espécies vegetais mais representativas na estrutura fitossociologia horizontal dos SAFs de várzea, Rio Juba afluente do Rio Tocantins, Cametá-PA 2001 - 1 ha

\begin{tabular}{cccc}
\hline NOME VULGAR & NOME CIENTÍFICO & $\begin{array}{c}\text { FAMÍLIA } \\
\text { BOTÂNICA }\end{array}$ & $\begin{array}{c}\text { DENSIDADE } \\
\text { RELATIVA \% }\end{array}$ \\
\hline ANDIROBA & Carapa guianensis & Meliaceae & 2,62 \\
CERUZEIRO & Allantoma lineata & Lecythidaceae & 0,09 \\
CINZEIRO & Terminalia amazonica & Combretaceae & 0,09 \\
\hline
\end{tabular}

Fonte: (RIBEIRO, 2002).

A espécie A. lineata é nativa da América do Sul e ocorre principalmente na Venezuela e na Bacia Amazônica e do Estado do Pará, Brasil, encontrada principalmente na mata pluvial Amazônica, florestas de igapó e várzeas, margens de rios e lugares pantanosos (Figura 2), é conhecida popularmente como "Cruzeiro" uma palavra indígena que significa árvores grandes e outros nomes como "Cheru", "xuru", "castanha-da-serra" e principalmente por "Ceru". Devido suas propriedades física e mecânica, é comercializada em várias partes do 


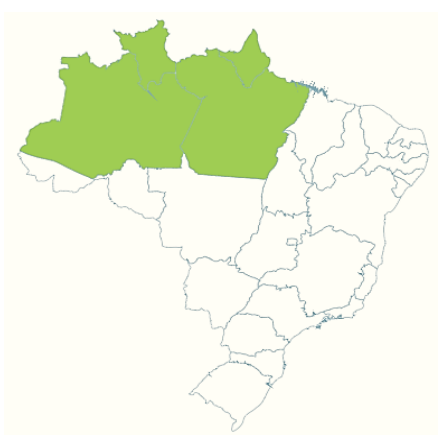

Figura 2 - Distribuição Geográfica da Espécie Allantoma Lineata.

Fonte: SMITH (2015).

O Ceru é a espécie menos importante da família das Lecythidaceae, como árvore de frutos oleaginosos (Figura 3). O fruto é um pixídio cilíndrico, de 10 a $15 \mathrm{~cm}$ de comprimento, por 4 a $5 \mathrm{~cm}$ de diâmetro, na abertura superior tem uma tampa (opérculo) que se destaca quando o fruto está maduro, deixando cair as sementes. Estas são numerosas, mas finas e compridas. Dentro de uma casca lenhosa de 3-4 mm de diâmetro, encerram uma amêndoa oleosa, fina, gostosa de comer, mas em proporção diminuta para interessar à indústria de óleos, os habitantes ribeirinhos usam como alimento. (PESCE, 2009).

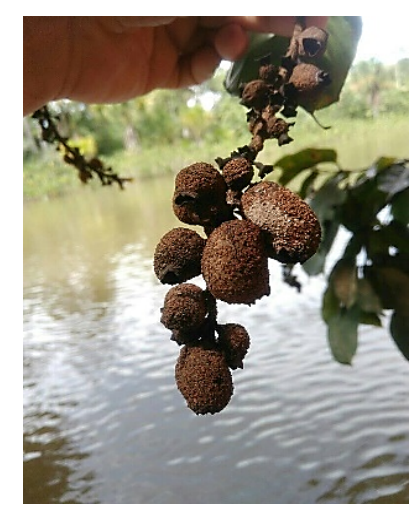

Figura 3 - Frutos de Allantoma Lineata nos estágios iniciais de desenvolvimento.

Fonte: Autor (2021).

Allantoma lineata parece ser recomendável para consumo humano visto que dispõem de quantidades relevantes de nutrientes, $\mathrm{O}$ valor biológico das proteínas está na mesma faixa que muitas outras proteínas vegetais, em um estudo de (ANDRADE et el. 1999) foi possível 
notar concentrações expressivamente altas de metionina, um aminoácido essencial.

\section{Análise biométrica}

Estudos de biometria de sementes podem fornecer informações úteis para conservação e exploração de uma fonte alimentícia de valor econômico, permitindo um incentivo contínuo da busca racional e uso eficaz de recursos naturais (GUSMÃO et al., 2006). Além disso, a biometria de frutos é uma importante ferramenta utilizada para avaliar a variabilidade dentro de uma população da mesma espécie, e as relações desta variabilidade com fatores ambientais, fornecendo maior conhecimento sobre aspectos ecológicos presentes de relevância na cultura estudada (MACEDO et al., 2009).

A biometria de sementes, pode contribuir para a tecnologia de produção de mudas de espécies nativas, contribuindo no conhecimento coletivo daquela espécie (ROELIS, 2017).

\section{Biscoito}

O biscoito surgiu na Antiguidade com a ideia de se amassar grãos entre duas pedras, misturando água àquela massa e secá-la ao fogo, tornando-a uma pasta seca e dura (SIMABESP, 2008).

Segundo Santos (2011), biscoito é o produto adquirido pelo amassamento e cozimento da massa preparada com farinhas, amidos, fermentada ou não, e outras substâncias alimentícias. Sua qualidade está relacionada com o sabor, a textura, a aparência entre outros fatores, e nos últimos anos vem se destacando como um produto de grande interesse comercial em decorrência de sua praticidade na produção, comercialização e consumo, além de possuir longa vida comercial.

Com lançamentos sempre no gatilho, expansão da oferta de produtos mais saudáveis e um parque industrial moderno, o setor brasileiro de biscoitos tem conseguido superar os contratempos macroeconômicos e apresentar resultados sólidos. Em 2014, as vendas do segmento cresceram $10,5 \%$ e totalizaram R $\$ 19,67$ bilhões em comparação a R $\$ 17,79$ bilhões no ano anterior. $\mathrm{O}$ varejo brasileiro de biscoitos é o segundo maior do mundo, com vendas na ordem de US\$ 9,19 bilhões (ABIMAPI, 2015). 


\section{METODOLOGIA}

A pesquisa foi realizada no Laboratório de Alimentos da Universidade do Estado do Pará, em Cametá. As castanhas de Ceru foram colhidas manualmente, em início de deiscência, em áreas distintas de ocorrência natural da espécie. Após colheita, os frutos foram acondicionados em sacos plásticos e levados ao laboratório. Em seguida, foram rigorosamente selecionadas segundo a presença de injúrias mecânicas e sanidade, lavadas em água corrente e assim submetidas à análise biométrica.

\section{Análise biométrica}

Para a análise biométrica, 80 (oitenta) sementes foram tomadas aleatoriamente de uma amostra composta, recém-coletada da espécie. De cada semente determinou-se a massa fresca (MF) em balança digital (SHIMADZU) e o comprimento longitudinal (CL), largura mediana (L) e a espessura mediana (E), com auxílio de um paquímetro digital (Nove, 54). $\mathrm{Na}$ Figura 5 encontra-se ilustrado as sementes de Ceru expostas para a análise biométrica.

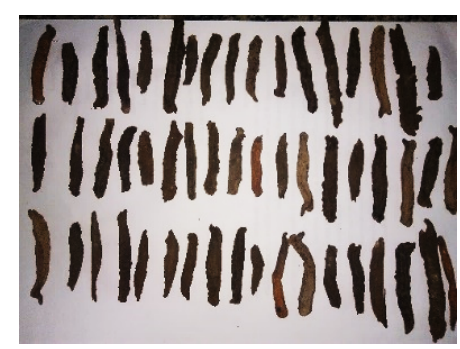

Figura 5 - Sementes dispostas de Allantoma Lineata

Fonte: Própria (2021).

\section{Processamento da amostra}

As amêndoas foram separadas e passaram por um processo de branqueamento por 15 minutos em água $90^{\circ} \mathrm{C}$, seguida de resfriamento por 5 minutos em água corrente $\left(22^{\circ} \mathrm{C}\right)$, para facilitar a remoção da casca das castanhas, inativar as enzimas que afetam a qualidade do produto e remover a quantidade de microrganismos de sua superfície.

As amostras para a análise físico-química foram obtidas a partir da trituração do material em multiprocessador da marca (Skymsen), até obtenção de uma farinha fina. 
Todas as análises a seguir foram realizadas em triplicata. As determinações dos teores de lipídios, proteínas, cinzas totais e umidade foram realizadas de acordo com as normas analíticas do Instituto Adolfo Lutz (2008), sendo os carboidratos calculados por diferença .

\section{Lipídeos}

Para a análise do perfil lipídico, foi feita uma extração contínua em um aparelho do tipo Soxhlet, com a utilização do solvente hexano de origem vegetal (INSTITUTO ADOLFO LUTZ, 2008).

\section{Umidade}

A análise de umidade foi determinada através da perda de peso da amostra após a remoção de água por evaporação, realizada em estufa com circulação e renovação de ar à temperatura de $105^{\circ} \mathrm{C}$, até peso constante (INSTITUTO ADOLFO LUTZ, 2008).

\section{Cinzas}

As amostras foram carbonizadas até cessar a liberação de fumaça e, posteriormente, calcinadas em forno mufla a uma temperatura de $540^{\circ} \mathrm{C}$, até obtenção de peso constante (INSTITUTO ADOLFO LUTZ, 2008).

\section{Acidez}

A determinação de acidez foi realizada através de titulação com $\mathrm{NaOH} 0,1 \mathrm{~N}$, tendo como indicador a fenolftaleína (INSTITUTO ADOLFO LUTZ, 2008).

\section{Cálculo de Energia}

Resolução RDC no. 360/03 da ANVISA, a qual prevê que para cálculo de energia deverão ser utilizados os fatores: $4,0 \mathrm{kcal} / \mathrm{g}$ para carboidrato, 4,0 kcal/g para proteína e 9,0 $\mathrm{kcal} / \mathrm{g}$ para lipídios (BRASIL, 2003). 
A obtenção da farinha de castanha de Ceru foi realizado através da modificação aa metodologia proposta por (COHEN, 2006) que realizou a elaboração de farinha de castanha do Brasil parcialmente desengordurada. O esquema está ilustrado na Figura 2.

\section{Fluxograma:}

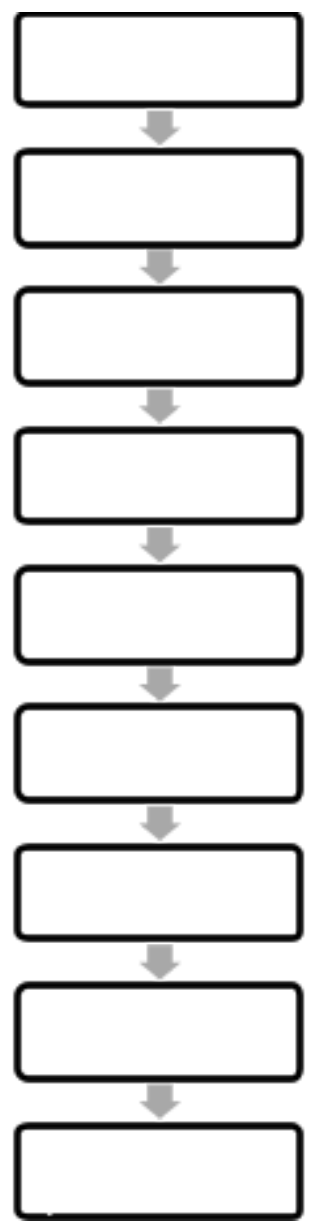

Figura 2 - Fluxograma do processo de obtenção da farinha de Allantoma Lineata.

\section{Seleção}

Primeiramente as castanhas sadias foram separadas das que apresentavam injúrias mecânicas ou sinas de decomposição (figura 3). 


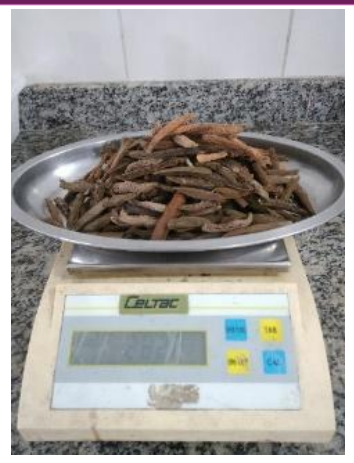

Figura 3 - Sementes de Allantoma Lineata "in natura".

Fonte: Autor (2021)

\section{Sanitização}

A lavagem com água foi empregada para a remoção das sujidades mais grosseiras da castanha e dessa forma garantir a sanidade das amêndoas para as próximas etapas. Depois de uma limpeza superficial usando apenas água corrente, as amêndoas foram submersas em água a 50 ppm de cloro ativo, durante 30 minutos.

\section{Branqueamento}

O Branqueamento foi realizado com o auxílio de uma panela e um termômetro, as castanhas permaneceram submersas na água até que o termômetro marcasse a temperatura de $90^{\circ} \mathrm{C}$. Depois desse momento, elas permaneceram por 15 minutos, depois elas foram resfriadas por 5 minutos em água corrente $\left(22^{\circ} \mathrm{C}\right)$. Essa etapa além de ajudar na remoção da casca da castanha, também inativa as enzimas que afetam a qualidade do produto e removem a quantidade de microrganismos de sua superfície, e foi realizada de forma manual com a ajuda de uma faca e uma tábua de corte.

\section{Descascamento manual}

A remoção da casca da castanha, foi feita de forma manual, com o auxílio de uma faca e uma tábua de corte.

\section{Lavagem}

Foi realizado uma lavagem utilizando água corrente $22^{\circ} \mathrm{C}$ por 5 minutos, com o 
objetivo de eliminar quaisquer sujidades que ainda poderia conter na castanha.

\section{Moagem}

A moagem foi realizada utilizando um multiprocessador (Skymsen), afim reduzir o tamanho das partículas e aumentar a superfície de contato das sementes com o ar quente da estufa e dessa forma facilitar o processo de desidratação.

\section{Secagem}

As castanhas foram secas em uma estufa com circulação de ar a uma temperatura de $70^{\circ} \mathrm{C}$ durante 48 horas. Obtendo pôr fim, a farinha da castanha de Ceru, como pode-se observar na Figura 4.

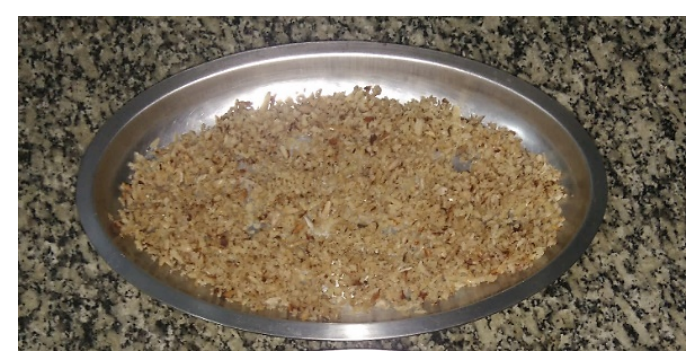

Figura 4 - Farinha da Semente sem casca de Allantoma Lineata.

Fonte: Autor (2021).

Envase em embalagem

A farinha ao fim do processo foi armazenada em um saco plástico de polietileno, depois foi retirado o ar dessa embalagem com a ajuda de uma embaladora a vácuo, e armazenada sob refrigeração a uma temperatura de $10^{\circ} \mathrm{C}$, até posteriores análises e elaboração dos biscoitos enriquecidos com a farinha de Ceru.

\section{Elaboração do biscoito a partir da farinha de Ceru}

Utilizou-se como matéria prima a amêndoa da castanha do Cruzeiro, proveniente da região de várzea do município de Cametá e os demais ingredientes (farinha de trigo, amido de milho, margarina, açúcar, ovos, sal e fermento químico) que foram adquiridos no comércio 
local.

Os biscoitos foram desenvolvidos no laboratório de Alimentos, da UEPA, Campus Cametá, por modificação da formulação proposta por Piovesana et al. (2013)

$\mathrm{Na}$ formulação do biscoito, foram acrescentados $18 \%$ de farinha de Castanha de Ceru (Tabela 1). Para o processamento dos biscoitos misturou-se a manteiga, farinha de Ceru, açúcar, trigo, fermento, amido de milho, gema de ovo e sal em um recipiente previamente senilizado, a mistura procede com a utilização das mãos até a massa apresentar textura cremosa.

Tabela 1 - Formulação única de Biscoito elaborado com adição de /farinha de Castanha de Allantoma Lineata.

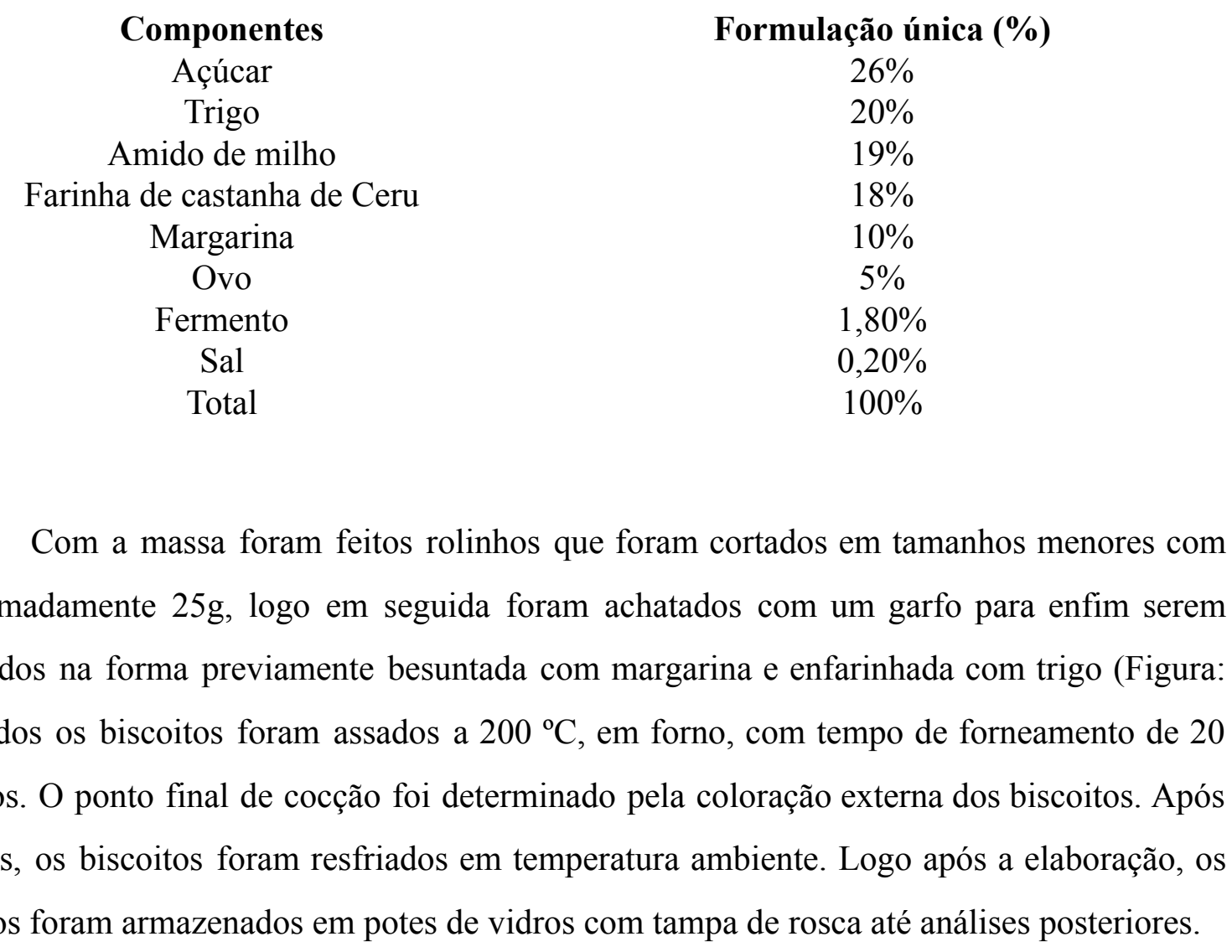

Formulação única (\%)
$26 \%$
$20 \%$
$19 \%$
$18 \%$
$10 \%$
$5 \%$
$1,80 \%$
$0,20 \%$
$100 \%$

aproximadamente $25 \mathrm{~g}$, logo em seguida foram achatados com um garfo para enfim serem colocados na forma previamente besuntada com margarina e enfarinhada com trigo (Figura: 5). Todos os biscoitos foram assados a $200{ }^{\circ} \mathrm{C}$, em forno, com tempo de forneamento de 20 minutos. O ponto final de cocção foi determinado pela coloração externa dos biscoitos. Após assados, os biscoitos foram resfriados em temperatura ambiente. Logo após a elaboração, os mesmos foram armazenados em potes de vidros com tampa de rosca até análises posteriores. 


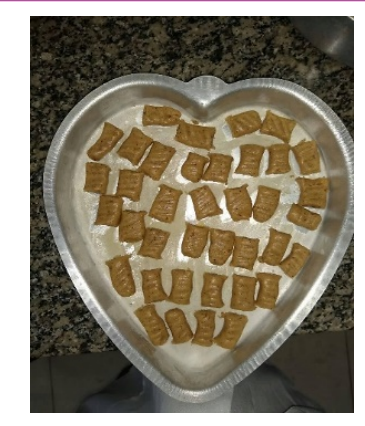

Figura 5 - Biscoito de farinha de Allantoma Lineata pronto para a cocção.

Fonte: Autor (2021).

\section{RESULTADOS E DISCUSSÃO}

\section{Análise Biométrica das castanhas}

$\mathrm{Na}$ Tabela 2 estão dispostos os resultados da análise biométrica das sementes de Allantoma Lineata. O peso das sementes variou entre $1,52 \mathrm{~g}$ e $0,32 \mathrm{~g}$ sendo respectivamente a maior e a menor, obtendo uma média de $0,86 \mathrm{~g}$, já no quesito largura, as sementes obtiveram os seguintes valores, maior $8,85 \mathrm{~mm}$ e menor $3,60 \mathrm{~mm}$, além disso a média apresentou $6,03 \mathrm{~mm}$, o Comprimento variou entre $13,45 \mathrm{~mm}$ e $6,15 \mathrm{~mm}$ com uma média de $8,26 \mathrm{~mm}$. As sementes apresentaram grande variação no parâmetro altura, observando-se que a maior foi $74,70 \mathrm{~mm}$ e a menor $29,15 \mathrm{~mm}$, obtendo uma média de $47,5 \mathrm{~mm}$, somado a isso, é possível destacar um desvio padrão elevado para este quesito o que pode estar relacionado à fatores ambientais não controlados, tais como condições naturais do ambiente, solo, clima e a idade da planta (SILVA, 2001), por outro lado, Aguiar (2018) trabalhando com duas agroindústrias de castanha do Brasil verificou que o tamanho de ambas eram semelhantes, apesar de as mesmas serem de diferentes localidades. Estudos mostraram que espécies arbóreas tropicais possuem relativa variabilidade quanto ao número de sementes e massa dos frutos (BRAGA et al., 2007; ZUFFO et al., 2014).

Tabela 2 - Resultados da biometria das sementes de Allantoma Lineata.

\begin{tabular}{cccccccc}
\hline ANÁLISE & MÉDIA & MAIOR & MENOR & VARIANCIA & DP & CV\% \\
\hline PESO DA AMENDOA (G) & 0,86 & 1,52 & 0,32 & 0,06 & 0,25 & 0,36
\end{tabular}




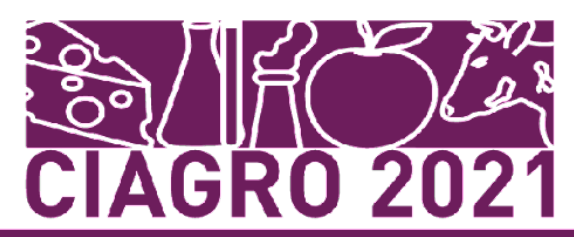

\begin{tabular}{c|cccccc|} 
ALTURA (MM) & 47,5 & 74,70 & 29,15 & 92,97 & 9,64 & 20,30 \\
LARGURA (MM) & 6,03 & 8,85 & 3,60 & 0,94 & 0,97 & 16,10 \\
COMPRIMENTO (MM) & 8,26 & 13,45 & 6,15 & 1,84 & 1,35 & 16,31 \\
\hline
\end{tabular}

Fonte: autores (2019).

Na Figura 6 encontram-se os dados referentes à distribuição de frequência para as características de Allantoma Lineata. Em relação ao peso das castanhas observadas é possível aferir que a maioria, cerca de 69\% está distribuída em duas classes que correspondem ao intervalo de $0,56 \mathrm{~g}$ a $1,04 \mathrm{~g}$, semelhante a este parâmetro a largura esteve concentrada em dois grupos correspondendo a $69 \%$ das sementes onde esteve em um intervalo de 4,65mm a $6,75 \mathrm{~mm}$. A altura das sementes ficou na classe correspondente $38,26 \mathrm{~mm}$ e $47,37 \mathrm{~mm}$ representando $39 \%$ das sementes. No quesito comprimento das sementes de A. Lineata a grande maioria das sementes $76 \%$ estavam distribuídas em duas classes, onde os valores oscilaram entre 6,15mm a 9,07mm, Estudos aplicando a Resolução 846/1976 (BRASIL, 1978) que estabelece uma Classificação e padronização para castanha do brasil, revela que a classificação das sementes quanto ao comprimento, tem grandes reflexos na comercialização de castanhas, favorecendo a baixa variabilidade. 

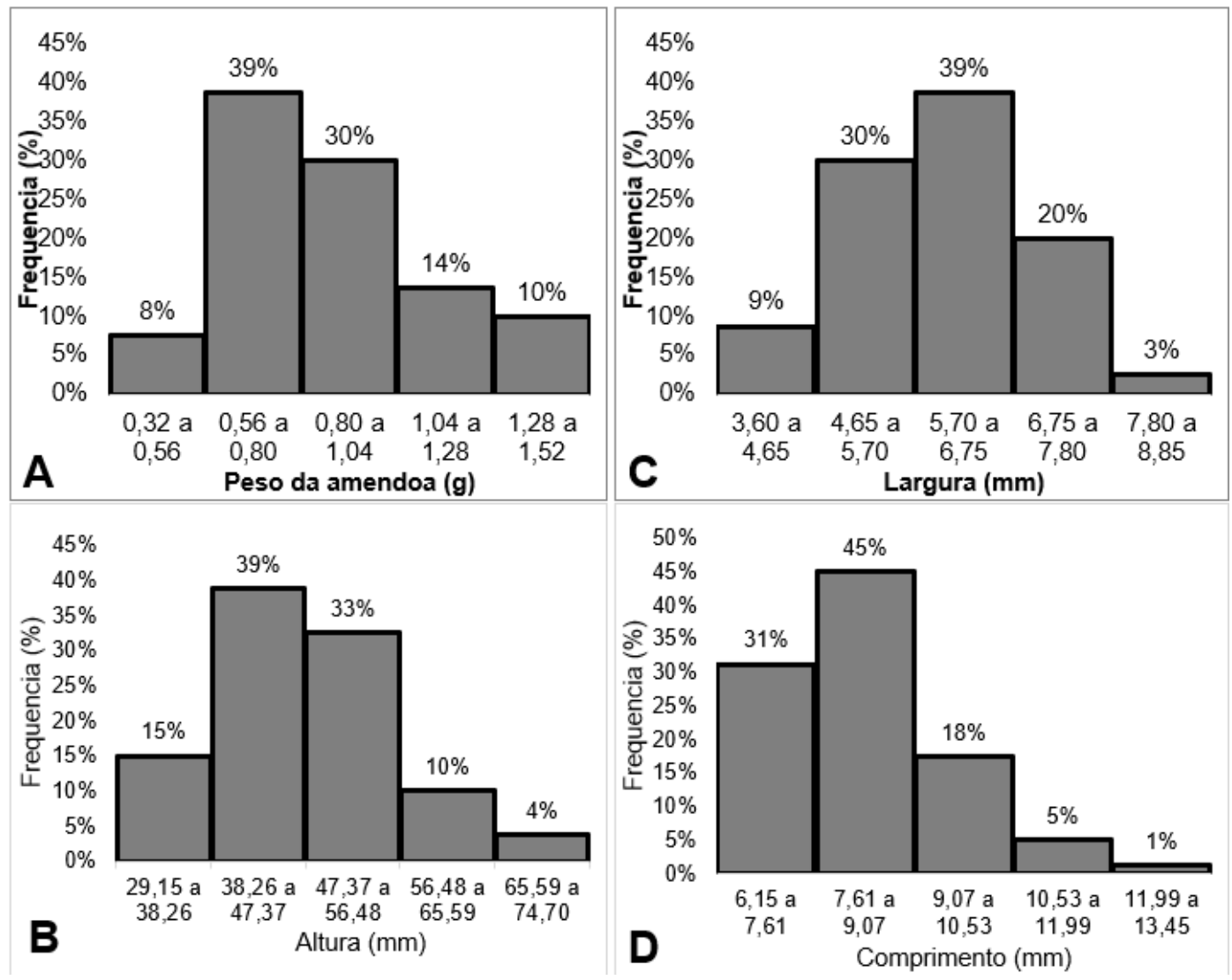

Figura 6 - Distribuição de frequência para as características de Allantoma Lineata.

Fonte: Autores (2019).

\section{Caracterização Físico-Química da Castanha de Ceru}

$\mathrm{Na}$ Tabela 3, são apresentados os resultados das análises físico-químicas das amêndoas de Ceru, com os respectivos desvios padrões, comparando com valores encontrados em literatura para castanhas da mesma família, como a castanha do Brasil e castanha de sapucaia.

A velocidade das principais reações químicas de transformação dos alimentos, como as reações de escurecimento enzimático e não enzimático, além das reações de oxidação lipídica, é geralmente aumentada pelo teor de atividade de água (Aa) (RIBEIRO, 2007). Com base nesses conhecimentos, as amêndoas da castanha de Ceru apresentaram teor de umidade em torno de 10,30\%, semelhante ao relatado por Carvalho (2012) para a castanha de sapucaia, que foi em torno de 10,20\%, o que é desfavorável ao aumento de vida de prateleira desses alimentos, pois o alto conteúdo de água prejudica na preservação desses alimentos por um 
longo período e contribui para a instabilidade química e microbiológica; já no estudo de Ferreira (2009) para a castanha do Brasil, o percentual de umidade média encontrado foi de $3,15 \%$. Estas variações refletem as diferenças das matérias primas, a mudança de safra, dentre outros aspectos.

Tabela 3 - Composição físico-química da castanha de Ceru (Allantoma lineata), castanha do Brasil (Bertholletia excelsa) e castanha de sapucaia (Ecythis pisonis).

$\begin{array}{cccc}\text { PARÂMETRO } & \begin{array}{c}\text { CASTANHA } \\ \text { DE CERU }\end{array} & \begin{array}{c}\text { CASTANHA DO BRASIL } \\ \text { (FERREIRA, 2009) }\end{array} & \begin{array}{c}\text { CASTANHA DE } \\ \text { SAPUCAIA } \\ \text { (CARVALHO, 2012) }\end{array} \\ \text { UMIDADE (\%) } & 10,30 \pm 0,30 & 3,15 \pm 0,02 & 10,20 \pm 0,68 \\ \text { LIPÍDIOS (\%) } & 57,24 \pm 1,32 & 61,00 \pm 1,32 & 54,80 \pm 4,15 \\ \text { PROTEÍNAS (\%) } & 24,57 \pm 1,58 & 15,60 \pm 0,29 & 26,82 \pm 2,60 \\ \text { CINZAS (\%) } & 2,05 \pm 0,02 & 3,13 \pm 0,04 & 3,17 \pm 0,50 \\ \text { CARBOIDRATOS (\%) } & 5,84 & 17,12 & 5,01 \\ \text { VALOR CALORICO (K } & 636,80 & 680,20 & 620,52 \\ \text { CAL. 100G -1) } & & & \end{array}$

O teor de lipídios na castanha do Brasil (61\%) é maior do que na castanha de Ceru analisada neste estudo. Já em relação a castanha de sapucaia, esta possui menor conteúdo de lipídios $(54,80 \%)$ em relação à castanha de Ceru.

A análise de proteínas totais da castanha de Ceru apresentou um valor mais elevado $(24,57 \%)$ quando comparado com o trabalho de Amaral et al. (2006) para a castanha do Brasil $(15,60 \%)$, confirmando assim sua ótima fonte energética; já para a castanha de sapucaia analisada por Carvalho (2012) o valor foi em média de 26,82\% confirmando sua riqueza também como fonte proteica. As variações podem ser explicadas por diferença de tratos culturais, local de plantio e diferença de matéria-prima.

As amêndoas da castanha de Ceru apresentaram um teor considerável de cinzas (2,05\%), esse resultado apresenta-se próximo ao encontrado por Amaral et al. (2006) e Carvalho (2012), com médias de 3,13\% e 3,17\%, respectivamente.

Os valores médios da composição centesimal, realizada na amêndoa e casca da 
castanha do Ceru encontram-se na tabela 4.

Tabela 4 - Análise físico-química da amêndoa e da casca da Allantoma lineata.

\begin{tabular}{lcc}
\hline \multicolumn{1}{c}{ ANÁLISE } & AMÊNDOA DE CERU & CASCA DE CERU \\
\hline UMIDADE (\%) & $10,30 \pm 0,30$ & $15,97 \pm 0,21$ \\
LIPÍDIOS (\%) & $57,24 \pm 1,32$ & $9,56 \pm 2,09$ \\
PROTEÍNAS (\%) & $24,57 \pm 1,58$ & $4,17 \pm 0,28$ \\
CINZAS (\%) & $2,05 \pm 0,02$ & $3,35 \pm 0,04$ \\
\hline
\end{tabular}

Fonte: Autores (2019).

O conhecimento dos constituintes físico-químicos dos alimentos é de suma importância para a avaliação do potencial da matéria-prima a ser utilizada no preparo de alimentos, bem como para o conhecimento do valor nutricional da mesma (CHISTÉ et al, 2009). Neste contexto, por efeito à carência de embasamento científico sobre a composição físico química da casca da castanha de Ceru, buscou-se comparar os parâmetros com cascas de outros frutos.

Analisando os resultados, podemos observar que o teor de umidade e cinzas para a casca da castanha de Ceru apresentaram uma média de 15,97\% e 3,35\%, respectivamente, ou seja, os valores encontrados para a casca foram maiores do que os valores da amêndoa, esses valores podem ser explicados pela absorção de umidade pelas casca, visto que está possui poros na sua superfície onde a agua pode acumular-se. Bramont et al. (2018) analisando a casca da cajarana obteve uma média para umidade em torno de $81,30 \%$, podendo ser considerada então produto de alta umidade.

O teor de lipídios se apresentou menor para a casca da castanha de Ceru $(9,56 \%)$ comparado a amêndoa $(57,24 \%)$, o mesmo aconteceu com o teor de proteína, onde a casca obteve média de $4,17 \%$ e a amêndoa $24,57 \%$.

\section{Caracterização Físico-Química do Biscoito com farinha de Ceru}

As características físico-químicas dos biscoitos adicionados de farinha de castanha de Ceru encontram-se expostos na tabela 5. 
Tabela 5 - Análise físico-química de Biscoito com farinha de semente de Allantoma Lineata.

\begin{tabular}{|c|c|}
\hline ANÁLISE & BISCOITO DE CERU \\
\hline UMIDADE (\%) & $0,68 \pm 0,18$ \\
\hline PH & 6,36 \\
\hline ACIDEZ (\%) & $13,89 \pm 3,10$ \\
\hline
\end{tabular}

Fonte: autores (2019).

O biscoito elaborado apresentou umidade de $0,68 \%$ e encontra-se em conformidade com a legislação vigente que estabelece valores de até 15\% (BRASIL, 2005). Oliveira et al. (2017) elaboraram cookies a partir de farinha da castanha de caju e encontraram valores superiores para o teor de umidade, que variaram de 2,64 a 8,09\%, que é bem superior ao teor de umidade dos cookies apresentados neste trabalho, e isso pode ser justificado pelos ingredientes utilizados, como açúcar mascavo e mel, que possuem umidade em torno de 5 e $20 \%$, respectivamente.

De acordo com Jardim (2010), mudanças físicas, como a crocância de biscoitos, dependem significativamente deste parâmetro. Segundo o autor, a viscosidade de alimentos sólidos amorfos é governada pela temperatura e pelo teor de água, acarretando mudanças na textura do produto. Dessa forma, a umidade presente traz informações importantes sobre a vida útil de um produto, bem como é um parâmetro do produto a ser modificado durante o processo de produção com o objetivo de aumentar a estabilidade dos alimentos (apud CLERICI,2013).

O pH é um fator de grande importância na limitação da capacidade de desenvolvimento de microrganismos no alimento. Em função deste parâmetro, de acordo com Soares e Freire - Júnior (1992) conforme citado por Oliveira (2017), os alimentos podem ser classificados em: pouco ácidos $(\mathrm{pH}>4,5)$, ácidos $(4,5$ a 4,0$)$ e muito ácidos $(<4,0)$. Constata-se, diante desta classificação, que o cookie de castanha de Ceru analisado é considerado pouco ácido $(6,36)$.

Os biscoitos de Ceru indicaram um teor de acidez em torno de $13,89 \%$, ou seja, apresentaram-se ácidos. Ribeiro (2007) revela que fatores como a temperatura e tempo de armazenamento estão relacionados a deterioração e aumento da acidez em óleos, condizendo com o tempo de armazenamento da farinha da castanha e o calor empregado no preparo da 
farinha, o que pode ter gerado subprodutos indesejáveis na matriz do biscoito.

\section{CONSIDERAÇÕES FINAIS}

As sementes de Allantoma Lineata apresentaram importante variação em suas características biométricas. Este comportamento se deve à variação genética e ambiental de cultivares, com isso, castanhas de outras regiões podem ser avaliadas.

A castanha de Ceru apresentou teores elevados de lipídios e proteínas, típico de sementes oleaginosas. No entanto, para a casca da castanha os valores foram inferiores. A casca apresentou teor de umidade e cinzas superior a amêndoa, demonstrando maior tendencia à degradação por microrganismos e maior quantidade de material inorgânico, respectivamente.

O biscoito elaborado com a castanha de Ceru, apresenta-se como fonte alimentícia nutritiva. Desta forma, a sua coleta e beneficiamento representa uma alternativa viável de geração de renda para famílias agroextrativistas localizadas nas regiões de várzea do município de Cametá/PA.

\section{REFERÊNCIAS}

ANDRADE, ELOISA HA, et al. Seed composition of Amazonian lecythidaceae species: part 3 in the series "Studies of edible Amazonian plants". Journal of food composition and analysis, 12.1: 37-51, 1999.

AGUIAR, AL da S.; DA SILVA, K. E.; ALVES, TCV. Biometria de sementes de Bertholletia excelsa Bonpl. em duas agroindústrias localizadas no Estado do Amazonas. In: Embrapa Amazônia Ocidental-Artigo em anais de congresso (ALICE). CONGRESSO AMAZÔNICO DE INICIAÇÃO CIENTIFICA, 3. 2018.

APARÍCIO, WC da S. Estrutura da vegetação em diferentes ambientes na Resex do Rio Cajari: interações solo-floresta e relações com a produção de castanha. Embrapa Amapá-Tese/dissertação (ALICE), 2011.

ABIMAPI. Associação brasileira das indústrias de biscoitos, massas alimentícias e pães \& bolos industrializados. Estatísticas - Biscoitos, 2015.

BRASIL. Ministério da Saúde. Agência Nacional de Vigilância Sanitária. Resolução RDC n 263, de 22 de setembro de 2005. REGULAMENTO TÉCNICO PARA PRODUTOS DE CEREAIS, AMIDOS, FARINHAS E FARELOS. Diário Oficial da República Federativa do Brasil, Poder executivo, Brasília, DF, set. 2005.

BRASIL. Ministério da Agricultura Pecuária e Abastecimento. PORTARIA Nº 846, DE 08 DE NOVEMBRO DE 1976. Especificações para a Padronização, Classificação e Comercialização Interna da Castanha do Brasil. Diário Oficial da República Federativa do 
Brasil, Poder executivo, Brasília, DF, nov. 1976.

BRASIL, Anvisa. Resolução RDC no 360, de 23 de dezembro de 2003. Ministério da Saúde - MS. Agência Nacional de Vigilância Sanitária - Anvisa. 2019

BRAMONT, W. B.. et al. Comparação da Composição Centesimal, Mineral e Fitoquímica de Polpas e Cascas de Dez Diferentes Frutas. Revista Virtual de Química, v. 10, n. 4, 2018.

BERNAL, R. A. et al. Wood anatomy of Lecythidaceae species called "Tauari". IAWA Journal, v. 32, n. 1, p. 97-112, 2011.

BRAGA, L.F. SOUSA, M.P. GILBERTI, S. CARVALHO, M.A.C. Caracterização morfométrica de sementes de castanha de sapucaia (Lecythis pisonis Cambess Lecythidaceae). Revista de Ciências Agro-Ambientais, v.5, n. 1, p.111-116, 2007.

CARDARELli, H. R.; OLIVEIRA, A. J. Conservação do leite de castanha-do-Pará. Scientia Agricola, Piracicaba, v. 57, n. 4, p. 617-622, 2000.

CARVALHO, I. M. M. et al. Caracterização química da castanha de sapucaia (lecythis pisonis cambess.) Da região da zona da mata mineira. Bioscience jornal. v. 28, n. 6, 2012.

CARVALHO, J. O. P. Dinâmica de florestas naturais e sua implicação para o manejo florestal. In: Embrapa Amazônia Oriental-Artigo em anais de congresso (ALICE). Resumos expandidos. Belém, PA: EMBRAPA-CPATU: DFID, 1999.

CARVALHO, M. G. et al. Formulation and sensory acceptance of cereal-bars made with almonds of chichá, sapucaia and gurguéia nuts. The Open Food Science Journal, 5.1. 2011.

CHISTÉ, R. C. et al. Características físicas e físico-química da casca de mangostão em três períodos da safra. Embrapa Amazônia Oriental-Artigo em periódico indexado (ALICE), 2009.

CLERICI, M. T. P. S. et al. Qualidade física, química e sensorial de biscoitos tipo cookies elaborados com a substituição parcial da farinha de trigo por farinha desengordurada de gergelim. Brazilian Journal of Food Technology, v. 16, n. 2, p. 139-146, 2013.

COSTA, P. A. et al. Phytosterols and tocopherols content of pulps and nuts of Brazilian fruits. Food Research International, v. 43, n. 6, p. 1603-1606, 2010.

CRAVO, A. B. Frutas e ervas que curam: usos, receitas e dosagens (5. ed.). São Paulo: Emus, p. 456, 1995.

FERREIRA, E. de S. et al. Caracterização físico-química da amêndoa, torta e composição dos ácidos graxos majoritários do óleo bruto da castanha-do-brasil (Bertholletia excelsa HBK). Alimentos e Nutrição Araraquara, v. 17, n. 2, p. 203-208, 2009.

GUSMÃO, Eduardo; DE ALMEIDA VIEIRA, Fábio; DA FONSECA JÚNIOR, Élcio Meira. Biometria de frutos e endocarpos de murici (Byrsonima verbascifolia Rich. ex A. Juss.). Cerne, v. 12, n. 1, p. 84-91, 2006.

GLÓRIA, M. M.; REGITANO-D'ARCE, M. A. B. Concentrado e isolado protéico de torta de Castanha-do-Pará: obtenção e caracterização química e funcional. Ciênc. Tecnol. Alim., Campinas, v.2, p. 240-245, 2000.

INSTITUTO ADOLFO LUTZ. Normas Analíticas do Instituto Adolfo Lutz: métodos químicos e físicos para análise de alimentos. 4. Ed. São Paulo, 2008.

LORENZI, H. Arvores brasileiras: manual de identificagao e cultivo de plantas arbéreas nativas do Brasil. Nova Odessa: Plantarum, p. 368, 1992.

MACEDO, M. L. C. et al. Biometria de frutos e sementes e germinação de Magonia 
pubescens ST. Hil (sapindaceae). Revista Brasileira de Sementes, v. 31, n. 2, 2009.

MORI, S. A. A família da castanha-do-pará: símbolo do Rio Negro. Florestas do Rio Negro, p. 119-142, 2001.

MÜlleR, C. H.; FIGUEIRÊDO, F. J.; KATO, A. K.; CARVALHO, J. E. U.; STEIN, R. L. B.; SILVA, A. de B. A cultura da castanha-do-brasil. Belém: EMBRAPA-CPATU Brasília, DF, 65p. 1995.

OLIVEIRA, S. N. et al. Elaboração e caracterização de biscoitos adicionados de farinha de castanha de caju com diferentes adoçantes. Revista brasileira de agrotecnologia, v. 7, n. 2, p. $145-150,2017$.

PIOVESANA, A. BUENO, M. M..; KLAJN, V. M. Elaboração e aceitabilidade de biscoitos enriquecidos com aveia e farinha de bagaço de uva. Brazilian Journal Food Technology, Campinas-SP, v. 16, n. 1, p. 68-72, 2013.

PROCÓPIO, L. C.; SECCO, R. S.. A importância da identificação botânica nos inventários florestais: o exemplo do "tauari" (Couratari spp. e Cariniana spp.-Lecythidaceae) em duas áreas manejadas no estado do Pará. 2008.

PESCE, C. Oleaginosas da Amazônia. IICA, Brasília, DF (Brasil), 2009.

TEIXEIRA, M.; CARDOSO, A. Varzeas da Amazonia. Caracterizacao e uso na Producao Agricola. Facultad de Ciencias Agrarias do para, 1991.

RAMOS, C. A. P. Possibilidades de Otimização do uso Florestal para Pequenos Produtores nas Várzeas Amazônicas: Um Estudo na Costa Amapaense. 2000.

RIBEIRO, RN da S. Avaliação do potencial de sustentabilidade de unidades produtivas agroflorestais em várzeas de influência flúvio-marinha, Cametá-pará. 2002.

RIBEIRO, E. P.; SERAVALLI, E. A. G. Química de alimentos. Editora Blucher, 2007.

RIBEIRO, R. N. S.; SANTANA, A. C.; TOURINHO, M. M. Análise exploratória da socioeconomia de sistemas agroflorestais em várzea flúvio-marinha, Cametá-Pará, Brasil. Brazilian Journal of Rural Economy and Sociology (Revista de Economia e Sociologia Rural-RESR), v. 42, n. 1346-2016-105089, p. 133-152, 2004.

ROELIS, B. V. et al. Caracterização morfológica de sementes de Castanheira-do-Brasil oriundas de floresta nativa e plantio comercial da região norte do estado Mato Grosso. In: Embrapa Agrossilvipastoril-Artigo em anais de congresso (ALICE). In: JORNADA CIENTIFICA DA UNEMAT, 8., 2017, CACERES, MT. Unemat, 2017.

SALOMÃO R. P.; ROSA N. A.; NEPSTAD D. C.; BAKK A. Estrutura populacional e breve caracterização ecológica - econômica de 108 espécies arbóreas da floresta amazônica brasileira. Interciência. v. 20, n. 1, p 20 - 29, 1995.

SANTOS, Cintieley Araújo et al. Elaboração de biscoito de farinha de buriti (Mauritia flexuosa L. f) com e sem adição de aveia (Avena sativa L.). Revista Brasileira de Tecnologia Agroindustrial, v. 5, n. 1, p. 262-273, 2011.

SIMABESP - Sindicato da Industria de Massas Alimentícias e Biscoitos no Estado de São Paulo. 2008.

SMITH, N.P.,Mori, S.A.,Prance, G.T. 2015. Lecythidaceae in Lista de Espécies da Flora do Brasil. Jardim Botânico do Rio de Janeiro, 2015.

SILVA, R. S. M.; CHAVES, L.J. NAVES, R.V. Caracterização de frutos e árvores de cagaita (Eugenia dysenterica DC.) no sudeste do estado de Goiás, Brasil. Revista Brasileira Fruticultura, v. 23, n. 2, p. 330-334, 2001.

SOUZA, M. L.; MENEZES, H. C. Processamento de amêndoa e torta de Castanha-do-Brasil e farinha de mandioca: parâmetros de qualidade. Ciênc. Tecnol. 
Alim., Campinas, v.24, n.1, p. 120-128, 2004.

VALlilO, M. I., TAVARES, M., PIMENTEL, S. A., BADOLATO, E. S. G., \& INOMATA, FEDPGE E. I. Caracterização química parcial das sementes de Lecythis pisonis Camb. (Sapucaia). Acta Amazônica, 28(2), 131-131. 1998.

ZUFFO, A.M.; ANDRADE, F.R.; ZUFFO JÚNIOR, J.M.; Caracterização biométrica de frutos e sementes de baru (Dipteryx alata Vog.) na região leste de Mato Grosso, Brasil. Revista de Ciências Agrárias, v.37, n.4, p.463-471, 2014.

SANTOS, et al. EFEITO DA GRAMATURA SOBRE A RESISTÊNCIA AO CISALHAMENTO DA LINHA DE COLA DE DUAS MADEIRAS TROPICAIS: seru (Allantoma lineata) e marupá (Simarouba amara). p40.2. 2010. 